This item was submitted to Loughborough's Research Repository by the author.

Items in Figshare are protected by copyright, with all rights reserved, unless otherwise indicated.

\title{
What causes imbalance in complex service networks? Evidence from a public health service
}

PLEASE CITE THE PUBLISHED VERSION

http://dx.doi.org/10.1108/JOSM-03-2016-0077

PUBLISHER

(C) Emerald

VERSION

AM (Accepted Manuscript)

\section{PUBLISHER STATEMENT}

This work is made available according to the conditions of the Creative Commons Attribution-NonCommercialNoDerivatives 4.0 International (CC BY-NC-ND 4.0) licence. Full details of this licence are available at: https://creativecommons.org/licenses/by-nc-nd/4.0/

\section{LICENCE}

CC BY-NC-ND 4.0

\section{REPOSITORY RECORD}

Verleye, K., E. Jaakkola, lan Hodgkinson, Gyuchan Thomas Jun, G. Odekerken-Schroder, and J. Quist. 2019. "What Causes Imbalance in Complex Service Networks? Evidence from a Public Health Service". figshare. https://hdl.handle.net/2134/22583. 
WHAT CAUSES IMBALANCE IN COMPLEX SERVICE NETWORKS? EVIDENCE

FROM A PUBLIC HEALTH SERVICE

Verleye K, Jaakkola E, Hodgkinson IR, Jun GT, Odekerken-Schröder G, Quist J.

\title{
Journal of Service Management
}

\begin{abstract}
Purpose - Service networks are inherently complex as they comprise of many interrelated actors, often driven by divergent interests. This can result in imbalance, which refers to a situation where the interests of at least one actor in a network are not secured. Drawing on the "balanced centricity" perspective, this paper explores the causes of imbalance in complex service networks.
\end{abstract}

Design/methodology/approach - Adopting a qualitative case-based approach, this paper examines a public health service network that experienced imbalance that was detrimental to the lives of its users: the Mid-Staffordshire NHS Trust, UK. Drawing on service-dominant logic and stakeholder theory, case evidence provides insight into the origin and drivers of imbalance in complex public service networks.

Findings - The origin of imbalance stems from competing institutional logics of various actors (patients/public, employees, managers, regulatory bodies, etc.), but the degree to which these competing institutional logics lead to imbalance is moderated by accountability, communication, engagement, and responsiveness within the service network.

Research limitations/implications - By uncovering causes of imbalance in complex public service networks, this paper pinpoints important research avenues for developing the balanced centricity perspective.

Practical implications - The inherent existence of multiple parallel institutional arrangements makes networks imbalanced, but value creation can be achieved when the appropriate mechanisms are fostered to manage balance between divergent logics.

Originality/value - By examining imbalance as the underlying cause of network dysfunction, this research contributes to understanding of the dynamics in, and performance of, complex public service networks.

Keywords - Complex service systems, service networks, value co-creation, institutional logics, balanced centricity, public services, health services, stakeholder theory, servicedominant logic, Mid-Staffordshire Trust, NHS.

Paper type - Research paper. 


\section{What Causes Imbalance in Complex Service Networks? \\ Evidence from Public Health Services}

\section{Introduction}

In today's specialized markets, the creation of value increasingly takes place in complex service networks that are composed of multiple actors whom contribute to creating value for themselves and for other actors through resource integration and service exchange (Patricio et al., 2011; Pinho et al., 2014; Vargo and Lusch, 2008). This means that value creation for the individual beneficiary is dependent on the interconnected resources and activities of a multitude of actors - persons and/or organizations - who work towards common goals (Jaakkola and Hakanen, 2013). Consequently, the responsibility for the quality of the outcome is spread across the network, which means that failure in one part of the network may result in destruction of the overall value in the network (Tax et al., 2011). A notable recent example of such network failure emerged at the Mid-Staffordshire National Health Service (NHS) Trust in the UK, where at one hospital an estimated 400 to 1200 patients died between January 2005 and March 2009 as a result of poor quality of care (Campbell, 2013). Though positioned within a healthcare system that by international standards is deemed effective when compared against international equivalents (Ingleby et al., 2012; see Appendix A), the events that occurred at the Mid-Staffordshire NHS Trust illustrates how the complexity of modern public healthcare service networks with many interrelated actors can cumulatively contribute to an unacceptable service (Holmes, 2013).

While extant service reseach has explored how value is created and experienced in service networks (e.g., Pinho et al., 2014; Jaakkola and Hakanen, 2013), very few studies focus on service failure in a network setting (Tax et al., 2011). To shed light into why complex service networks such as the Mid-Staffordshire NHS Trust case may fail, it is critical to shift the perspective to a system-level, "many-to-many" perspective that takes 
different actors in the network and their interconnectedness into consideration (Pinho et al., 2014; Tax et al., 2013). Gummesson $(2007,2008)$ argues that each network actor is driven by their respective anticipation of value, by which a failure to take different aspirations into account may have negative repercussions for the creation of value in complex service networks. To highlight this viewpoint, Gummesson $(2007,2008)$ put forward the concept of "balanced centricity" that describes a situation where the interests of all actors in a network are secured. This view resonates with stakeholder theory that calls for "simultaneous attention to the legitimate interests of all appropriate stakeholders” (Donaldson and Preston, 1995, p. 67), which is expected to bring long-term value outcomes to network actors (Hillebrand et al., 2015).

To date, few researchers have investigated how complex service networks that include a wide variety of diverse actors, can strive for and/or reach balanced centricity. Notable exceptions include studies by Frow and Payne (2011), Quero and Ventura (2015), and Hillebrand et al. (2015) that provide preliminary insights into the importance of balance and ways to achieve this. While the insights garnered shed light on the drivers of balance, they do not explore why service network imbalance (i.e., the situation where legitimate interests of at least one actor in a complex service network are not secured) might occur in the first place. Since understanding value creation in complex networks is of pivotal practical and academic relevance in the increasingly systemic and fragmented service context, within public and private settings alike (e.g., Pinho et al., 2014; Ostrom et al., 2015), this research aims: to explore the origin and drivers of imbalance in complex service networks, thereby illuminating hindrances for value co-creation in such networks.

The study relies on the Mid-Staffordshire NHS Trust case, where unacceptable levels of service quality, reduced patient well-being, and high mortality rates illustrate how complex service networks that comprise many interrelated actors-such as patients/public, employees, 
managers, and a multiplicity of regulatory bodies-can spawn conflicting tensions resulting in imbalance and eventually diminished value outcomes for the network actors (Campbell, 2013; Holmes, 2013). Building on a thorough analysis of the rich and well-documented MidStaffordshire NHS Trust case, this paper proposes a framework that explicates how imbalance emerges in complex public health service networks. The main contribution of the paper is uncovering the origin and drivers of imbalance, and the notion that imbalance is the underlying cause of value destruction in complex service networks. These findings contribute to a better understanding of value co-creation in complex service networks that has been identified as a key research priority by Ostrom et al. (2015). This research makes propositions for the conditions under which imbalance leads to value destruction in complex service networks, which brings the concept of balanced centricity to an actionable level.

The remainder of this paper is organized as follows. First, we draw on servicedominant logic (SDL) and stakeholder theory to outline the conceptual background for value co-creation and balanced centricity in complex service networks. This is followed by a description of the Mid-Staffordshire NHS Trust case and data analysis. Building on this illustrative case, the paper proposes a framework for understanding the origin and drivers of imbalance in complex public health service networks and points to how value creation can be achieved when appropriate mechanisms are fostered to manage balance. The paper concludes by pinpointing important research avenues and practical implications.

\section{Theoretical Framework}

Value Co-Creation in Complex Service Networks

SDL regards all actors, whether businesses or consumers, as resource integrators who interact to gain resources for use in their respective value creation processes (Vargo and Lusch, 2008). These processes involve a range of stakeholders (Gummesson, 2007) who form 
service networks that provide contexts for value creation (Vargo and Lusch, 2008). Since “customers” might play an active role in service creation and delivery processes, and service providers also have the role of "beneficiaries" in reciprocal service exchanges, recent contributions to SDL move away from pre-designated roles as "customers" and "producers" to the more generic notion of “actors” (Vargo and Lusch, 2011).

More recently SDL explicitly calls for an actor-to-actor orientation to better understand value co-creation (Vargo and Lusch, 2016). An actor-to-actor orientation is valuable, in that value co-creation often results not from single encounters between two actors, but during a customer journey consisting of multiple encounters with different touchpoints of a variety of actors (Bitner et al., 2008; Patricio et al., 2011; Teixeira et al., 2012). McColl-Kennedy et al. (2012), for instance, show that the quality of life of cancer patients depends not only on their interactions with doctors and other health professionals (market-facing actors), but also on their interactions with family and friends (private actors) and support groups (public actors). Similarly, Tax et al. (2013) introduce the concept of service delivery networks to capture "two or more entities that, in the eyes of the customers, are responsible for the provision of a connected, overall service” (p. 457); however, each service provider also interacts with a variety of actors to integrate resources and exchange services. Consider, for instance, hospital physicians interacting with a variety of marketfacing and public actors, such as hospital management, local professionals, manufacturers, professional regulators, and different public bodies. A multitude of actors-involving people and/or organizations-can contribute to creating value for themselves and for other actors and jointly provide the context through which value gains its individual and collective assessment (Patricio et al., 2011; Pinho et al., 2014; Vargo and Lusch, 2008, 2011). In the context of public healthcare, the creation of value increasingly takes place in complex service networks 
composed of multiple actors for which the degree and nature of the relationship is imperfectly known (Pinho et al., 2014; van Riel et al., 2013; Vargo and Lusch, 2016).

Regarding the nature of the relationships among different actors in a complex health service network, several authors hold that these relationships may vary from low to high interdependence (Tax et al., 2013; van Riel et al., 2013). Regardless of the level of interdependence, however, each dyadic interaction with a network actor is embedded in a wide range of interactions with other network actors (Tax et al., 2013). In other words, actors and their interactions do not exist in isolation but as part of complex networks (Gummesson, 2007, 2008; Moller and Halinen, 1999). Moreover, following SDL the actions and interactions of different actors are enabled and constrained by institutions defined as "humanly devised rules, norms, and beliefs that enable and constrain actions" and institutional arrangements defined as "sets of interrelated institutions" (Vargo and Lusch, 2016). For example, hospital physicians may be influenced by the actions and underlying institutions of actors within their network, such as medical schools, hospital management, manufacturers, and government, which ultimately has implications for their interactions with patients. For instance, medical schools can affect the patient-physician relationship by teaching the physicians who perform surgery in the hospital, the hospital management by launching initiatives to improve the physician's operational efficiency, manufacturers by developing new surgery packs, and the government by changing reimbursement plans. Similarly, the hospital physician-patient relationship may be affected by actions and institutions of actors in the patient's network, as illustrated by recent evidence that frontline employees (such as hospital physicians) might perceive interactions among customers (such as patients interacting with peers) as job demands (Verleye et al., 2016).

Value creation for each actor thus depends on their own actions and institutions and the actions and institutions of other actors in a complex set of interactions and 
interdependencies (Pinho et al., 2014). Value co-creation therefore is not necessarily a dyadic or sequential process, but takes place in a complex network consisting of different types of relationships that indirectly influence value co-creation (Lusch et al., 2010). In sum, it is not only the number of actors but also the nature of the relationships among actors that render service networks complex (Voss and Hsuan, 2009).

\section{Balanced Centricity in Complex Service Networks}

Since the value co-creation process among actors depends on their own (inter)actions and institutions, as well as (inter)actions and institutions in each of the actors' networks, recent advancements in SDL call for adopting a network perspective on value co-creation (Vargo and Lusch, 2016). A distinction is noted here between an ego network and a whole network perspective: an ego network perspective concentrates on a focal actor (also known as "ego") and the actors with whom the focal actor has a relationship with, referred to as "alters", and all the links among those alters (Everett and Borgatti, 2005; Marsden, 1990). As mentioned, focal actors are not only affected by their alters but also by the alters of their alters. Therefore, this paper draws upon a complete or whole network perspective, which takes both direct and indirect links among different actors in complex service networks into consideration (Marsden, 1990). In complex service networks, the actions and institutions of one actor can have far-reaching positive and negative consequences for other actors. If the government launches a new reimbursement plan for specific types of surgery to support patients, for instance, this action might benefit not only patients but also surgeons and manufacturers; in contrast, the reimbursement plan might pose a burden on the social security system, which has implications for the citizenry, community, and/or nation. As illustrated in the example, actions and institutions of one actor might both facilitate and hinder the creation of value for other often loosely coupled actors in complex service networks (Frow and Payne, 
2011; Fry and Polonsky, 2004; Plé and Cáceres, 2010).

In this context, it is conceivable that actor needs and wants might be in conflict. Stakeholder theory holds that the interests of all actors merit consideration for their own sake and not merely because of their ability to meet the interests of another group of actors (Donaldson and Preston, 1995). In line with this reasoning, the notion of balanced centricity highlights a need to consider the interests of multiple actors including the beneficiary within a network frame (Gummesson, 2007). Recent research indicates that striving for balanced centricity contributes to the effectiveness and performance of organizations and is thus instrumental for creating economic advantages over the long-term (Hillebrand et al., 2015).

Despite these notions, only a handful of researchers have discussed how balanced centricity can be achieved. For example, Frow and Payne (2011) propose a five-step process to help focal firms move towards a more informed balance across different stakeholders, which includes (1) identifying all relevant actors, (2) determining their core values, (3) facilitating dialogue and knowledge sharing among different actors, (4) identifying opportunities for value co-creation, and (5) co-creating actor value propositions. Quero and Ventura (2015) explore the role of quality of information exchanges and actor-to-actor relationships to achieve balanced centricity in the creative industry. Hillebrand et al. (2015) stress the importance of a stakeholder-orientation, which focuses on "value co-creation in network relationships rather than just dyadic relationships and acknowledge the potential of indirect creation of value” (p. 412). Hillebrand et al. (2015) hold that complex value exchanges in networks require whole-systems thinking defined as "the capability of understanding the whole stakeholder value system” (p. 416). To achieve this end, firms need to be able to deal with and identify all actors within the system and understand the complex structure of that system. Additionally, firms require capabilities to deal with explicit tensions between the interests of multiple actors, thereby showing the importance of paradoxical 
thinking defined as "the degree to which the firm is capable of accepting and learning from tensions between stakeholder interests” (p. 419). Finally, firms embedded in complex networks with dispersed control require democratic thinking to share control over decisionmaking with a multitude of stakeholders (Hillebrand et al., 2015).

Although highlighting the perspectives of multiple actors, the aforementioned studies subscribe to a focal actor or ego network perspective and do not explicitly investigate network imbalance. Provan et al. (2007) argue for the adoption of a whole network perspective where multilateral ties among multiple actors are taken into consideration, which can have important implications for individual network members by avoiding exaggeration of the importance of actions and events of individual actors and taking simultaneous and collective events and actions into consideration. As a consequence, individual network members might also benefit from a whole or complete network perspective, in that a whole or complete network perspective does not constrain researchers to focus exclusively on individual network members, such as end users.

\section{The Mid-Staffordshire NHS Trust Case}

The Research Setting: Healthcare and the NHS

The healthcare setting is particularly complex given the nature of serving 'reluctant consumers', such that the presence or possibility of illness thrusts people into the healthcare service. Serving a customer who arrives with some combination of illness, pain, uncertainty, and fear presents a unique challenge. These circumstances can cause medical customers to be far more emotional, sensitive, dependent, and/or demanding than they would normally be as consumers (Berry et al. 2004, Raghunathan et al., 2006). Moreover, according to Berry and Bendapudi (2007) medical customers might be harmed instead of healed by hospital-acquired infections and diagnosis and treatment errors, leading to avoidant coping strategies and 
suboptimal decision-making and behaviours (Duhachek, 2005). In this context, health systems typically have several bodies for regulating particular aspects of care such as patient safety to safeguard medical customers' interests, such as the Healthcare Commission and Monitor in the NHS. In the meanwhile, health systems experience pressure to reduce cost and improve the efficiency of service delivery (World Health Organization, 2016). In the UK, the NHS is the world's fifth largest employer with approximately 1.3 million employees and has a total budget (2015-16) of $£ 136.7 \mathrm{bn}$ of which $£ 116.6 \mathrm{bn}$ is managed by NHS England (Campbell and Duncan, 2016). The money for the NHS comes from the Treasury and is mostly raised through taxation; approximately half (47\%) of the NHS budget is spent on acute and emergency care, while general practice, community care, mental health and prescribing each account for approximately 10\% (NHS England, 2014). Between 2011 and 2015, the NHS was charged with a £20bn savings drive. In response to these pressures, the UK Department of Health, which is responsible for funding health and social care, has encouraged all NHS Trusts to reduce fees on external consultancy and make further in-house improvements, but 66 NHS Trusts incurred overspend of more than $£ 750 \mathrm{~m}$ at the end of 2013-14 (Campbell, 2014). In this sense, all NHS Trusts that manage care in either a geographical area and/or a specialized function (NHS, 2016) are confronted with a growing need to use all available resources effectively and to provide high-quality medical provision at significantly reduced costs.

\section{Case Introduction: the Mid-Staffordshire NHS Trust}

To gain more insight into the origin and drivers of imbalance in complex service networks from a whole network perspective, we analyze the case of the Mid-Staffordshire NHS Trust. The Mid-Staffordshire NHS Trust comprised two hospitals that shared approximately 450 inpatients with 3000 employees serving a local population of approximately 320,000 
(Holmes, 2013). Between January 2005 and March 2009, Stafford Hospital, one of the two hospitals of the Mid-Staffordshire NHS Trust, experienced shocking levels of dissatisfaction and mortality rates (Campbell, 2013). When the levels of performance were uncovered, the Mid-Staffordshire NHS Trust and specifically Stafford Hospital was first subjected to a nonstatutory inquiry that focused on the hospital management and staff, but did not consider the involvement of the wider system in what went wrong as this was beyond the inquiry's Terms of Reference (Francis, 2013). However, this inquiry recommended a need for further investigation of the wider network to consider why these issues had not been detected earlier and to ensure that any necessary lessons were learned. The subsequent public inquiry was charged to investigate the interactions between the Mid-Staffordshire NHS Trust and a wide variety of agencies with responsibilities for oversight, contracting and regulation of healthcare services and professionals at the relevant time and the deficiencies in the system which allowed the events specifically at Stafford Hospital to pass unnoticed or without effective reaction for so long (Francis, 2013). Consequently, this case is well suited to illustrate a situation of imbalance in a complex public health service network where the needs and wants of different actors, including the end users, have not been met. Table 1 provides a timeline of key events within the case that led to the public inquiry report and its publication, along with a list of thematic recommendations derived from the inquiry.

\section{Please insert Table 1}

\section{Data and Analysis}

The case analysis is based upon an extensive independent public inquiry report on the MidStaffordshire NHS Trust conducted following appalling conditions of care between 2005 and 2008 (Francis, 2013). The decision to use the public inquiry report for our research relied on 
the fact that evidence for the causes of the imbalanced situation was gathered from a wide variety of witnesses in terms of numbers (cf. 352 individual witness statements) and functions (patients and relatives, healthcare professionals, officials, politicians, etc.). Additionally, different types of oral and written evidence were included, such as interviews, written statements, reports, and regulatory documents. This evidence was extensively described in the public inquiry report before discussing the lessons learned from this evidence and key recommendations. Taken collectively, these factors contribute to the validity of the public inquiry report (Yin, 2014). Next, core participants were informed about the inquiry's intentions and procedural protocols and this information was also shared with the wider public and press as they have unfolded rather than after the event, thereby increasing the reliability of the public inquiry report. Furthermore, the reliability of the public inquiry report was improved by taking live note transcripts of all evidence given, which were first shared with the core participants and subsequently with the wider public and press (after consultation as necessary). Finally, reports from public inquiries in the UK (including the Mid-Staffordshire public inquiry report) have been considered as valuable data sources in previous research (Hutchison, 2016). As a consequence, the public inquiry report allows for an examination of a case where imbalance was inherent throughout a complex service network.

To improve our understanding of the origin and drivers of imbalance from a whole network perspective, a qualitative case-based approach is adopted. The entire contents of the report-involving an executive summary (121 pages) and three volumes (1783 pages)-were imported in Nvivo. After reading several times through the data to familiarize with the data, the data coding began by categorizing units of data into analytical codes, which is a process called open coding (Miles \& Huberman, 1994; Strauss \& Corbin, 1998). Specifically, the open coding process involved capturing each unique idea or thought by means of in vivo 
codes or codes involving simple descriptive phrases. Next, we compared open codes for similarities and differences, thereby identifying more abstract categories. During this process, we relied on the concept of balanced centricity and key concepts in SDL and stakeholder theory (i.e., actors, actions, rules/norms/beliefs, and interests). In other words, the data were analyzed through an iterative process of comparison between theoretical concepts and emergent categories, which is in line with Eisenhardt's (1989) and Yin’s (2014) suggestion for developing theory from case study research. By doing so, we identified different aspects of imbalance (e.g., "not observing standards of care") and different types of actors (e.g., "local community”), actions (“lack of corrective actions”), norms/rules/beliefs (“wait and see attitude”), and interests (“patient care logic”).

Next, we investigated the relationships among these abstract categories, thereby using code matrices in line with the recommendations of Miles and Huberman (1994). Further analysis of the code matrices revealed differences and similarities in terms of interests, rules, norms, beliefs, and actions across different actors. As a consequence, we decided to report the different interests, norms, rules, and beliefs of different actors as the emergent theme “competing institutional logics” and the actions and rules/norms/beliefs across actors as the emergent themes “ lack of accountability”, "lack of communication”, “lack of engagement”, and "lack of responsiveness" (see Appendix B and C). With regard to the last four themes, rules/norms/beliefs and actions were grouped in overarching themes, because the code matrices revealed that specific types of actions (e.g., "lack of corrective action”) were highly related to specific types of rules/norms/beliefs (e.g., "wait and see attitude”). The imbalance that caused the critical situation to emerge in the Mid-Staffordshire NHS Trust case is found through all of these themes, which are now discussed. The origin of imbalance and its drivers are then considered in the discussion section. 


\section{Causes of Imbalance in the Mid-Staffordshire NHS Trust Case}

Our analysis resulted in the identification of five key themes that help explain the emergence of imbalance in the studied case: competing institutional logics, lack of accountability, lack of information, lack of engagement, and lack of responsiveness. In what follows, each of these themes and their link with imbalance is discussed.

\section{Competing Institutional Logics}

Our analysis of the interests, norms, rules, and beliefs-and thus institutional logics-in the network revealed clear contradictions between a patient care logic and business logic. The former involves a focus on the patient, patient care, patient safety, quality of care, and public trust, whereas the latter focuses on financial, organizational, governance issues and achieving status and success. A comparison of the institutional logics of different key network actors revealed that patient care logic and business logic acted as competing institutional logics, in that these logics were held by different network actors. While it is evident that some actors within the system, such as nursing staff, did show compassion toward patients (cf. patient care logic), the case illustrates that different actors within the system adopted business logic at the detriment of a patient care logic. More particularly, there was little support for the patient care logic among hospital management (see Quotes 1a and 1b), governmental actors, local authorities, non-departmental public bodies (see Quote 1c), and the trust as a whole (see Quote 1d). In other words, service provision was compromised as a result of priorities pursued and actions executed that were in direct conflict with patient care. The next sections elaborate on the reasons for the prevalence of the business logic at the detriment of a patient care logic. 
Quote 1a: "This failure [of the Trust Board] was in part the consequence of allowing a focus on reaching national access targets, achieving financial balance and seeking foundation trust status to be at the cost of delivering acceptable standards of care." (p. 3)

Quote 1b: "Management thinking [at the Trust] during the period under review was dominated by financial pressures and achieving FT status, to the detriment of quality of care.” (p. 13)

Quote 1c: “The Strategic Health Authority's [SHA] focus was on financial and governance issues, as the key criteria valued by the DH and Monitor. However, the SHA should not have allowed itself to forget that the purpose of any development in the NHS should be to improve the ability of the system to care for its patients.” (p. 50)

Quote 1d: “The focus of the system resulted in a number of organisations failing to place quality of care and patients at the heart of their work. Finances and targets were often given priority without considering the impact on the quality of care.” (p. 65)

\section{Lack of Accountability}

Throughout the case there are numerous examples of actors assuming that monitoring, performance management and/or intervention was the responsibility of someone else, such taken for granted assumptions that others had responsibility in terms of quality of care passed accountability from one actor to another with little attempt to collect quality information in a systematic way between actors. As illustrated by the example, the case material suggests that several actors involved in the Mid-Staffordshire NHS Trust case experienced misunderstandings about their own functions and responsibilities and those of other actors in 
the NHS (see Quote 2a), and/or did not pay sufficient attention to their specific responsibilities (see Quote 2b), leading to overreliance on other actors in the system. In other words, actions related to taking responsibilities (cf. overreliance on other actors in the system) are driven by rules, norms, and beliefs in terms of responsibilities (cf. misunderstanding about responsibilities). A lack of accountability involves thus both rules, norms, and beliefs and actions related to (taking) responsibilities.

Quote 2a: “The role expected of SHAs was challenging (...) There also appears to have been a lack of clarity with regard to the extent to which SHAs were expected to address concerns about quality and safety.” (p. 49)

Quote 2b: “I do not think it was the County Committee's responsibility to go and find out what the views of people were. In a sense it would have been pointless to do this given the vast and frequently diametrically opposed range of views amongst different members of the public" (p. 549)

Further analysis revealed that this lack of accountability among different actors was found to be in part due to norms, rules, beliefs, and actions of actors with regulatory power, as illustrated by a lack of clarity on the regulations (see Quote 2c), regulatory gaps in terms of responsibilities and accountabilities (see Quote 2d), and constant reorganization of NHS structures (see Quote 2e). As a consequence, actors with regulatory power shape actors' norms, rules, beliefs and/or actions related to accountability, thereby leading to a lack of accountability at the system level.

Quote 2c: "It is right to conclude that there had been a lack of clarity in relation to the formal allocation of responsibility.” (p. 527)

Quote 2d: “responsibilities and accountabilities of external agencies were not well 
defined, often resulting in "regulatory gaps" or failure to follow up warning signs." (p. 64)

Quote 2e: “constant reorganisation of NHS structures, often leading to a loss of corporate memory and misunderstandings about an organisation's functions and responsibilities.” (p. 65)

\section{Lack of Communication}

The case evidence suggests that relevant information pertinent to the degree to which interests of actors were secured was not properly disseminated and discussed throughout the system, because a multitude of actors in the system gave insufficient consideration to the importance of information sharing and communication (see Quote 3a and 3b). At the heart of these communication failures were a false belief among different actors in the system that others would keep them informed rather than actively seeking and communicating information independently (see Quote 3c). This evidence suggests that norms, rules, and beliefs in relation to communication (cf. low importance of and false beliefs in terms of information sharing) lead to communication-related actions (cf. not properly disseminating information and waiting for information rather than actively seeking information).

Quote 3a: "A failure of communication between the many agencies to share their knowledge of concerns.” (p. 49)

Quote 3b: There was insufficient consideration given to the importance of communication with regulatory and supervisory bodies in order to ensure that relevant information pertinent to patient safety was properly disseminated, discussed and appropriate action considered.” (p. 60) 
Quote 3c: “There was, however, an unhealthy attitude of leaving it up to Monitor to find what they were looking for, rather than the Trust openly and proactively seeking out information about the problems of which Monitor needed to be aware.” (p. 393)

Not only were issues surrounding communication-related actions present at the level of the whole system, it was endemic between all actors, for example, small, volunteer groups representing the public voice did not have the means or the authority to provide an effective channel of communication through which other types of actors in the healthcare system could benefit from the enormous resource of patient and public experience waiting to be exploited. Similar issues were also present among similar types of actors, such as members of the same organization (see Quote 3d) or similar types of organizations that failed to connect pieces of information that would have shown the full consequences of action/inaction (see Quote 3e). As illustrated by these examples, issues surrounding communication-related actions among a multitude of actors at all levels of the system led to an inadequate understanding of the degree to which patients' interests were secured at the system level.

Quote 3d: "The surgeons worked independently of one another; there was little communication between them" (p. 121)

Quote 3e: "Communication of intelligence between regulators needs to go further than sharing existing concerns identified as risks, and it should extend to all intelligence which when pieced together with that possessed by partner organisations may raise the level of concern.” (p. 56)

\section{Lack of Engagement}

The data revealed that business performance was given priority without considering the impact on the quality of care due to high levels of disengagement throughout the system, with 
the case reporting that there was insufficient sense of engagement for ensuring quality care and thus engagement with the patients and the public (see Quote 4a) and a general lack of effective engagement with patients and the public (see Quote 4b). In other words, the lack of engagement among a wide variety of actors reflects both norms, rules, and beliefs (cf. insufficient sense of collective engagement in Quote 4a) and actions (cf. doing little to reach out to the public in Quote 4b).

Quote 4a: “The Trust lacked a sufficient sense of collective responsibility or engagement for ensuring that quality care was delivered at every level.” (p. 65)

Quote 4b: "The forum did little to reach out to the public to obtain wider views. There was a lack of effective engagement with the public." (p. 504)

Further analysis reveals that a lack of engagement actions towards patients and the public depends on actors' beliefs about the appreciation for engagement with patients and the public by other actors and the consequences of engagement with patients and the public for themselves (see Quote 4c). In other words, actors' engagement actions are driven by their engagement beliefs, which in turn depend on other actors' engagement actions and beliefs. Additionally, there is some evidence that actors' engagement with patients and the public might also depend on the degree to which they experience engagement from other actors towards them (see Quote 4d and 4e). In sum, a complex tangle of disengagement among a wide variety of actors ultimately led to a lack of engagement with the patients and the public.

Quote 4c: "clinicians did not vigorously pursue with management concerns they may have had. The reason for this was in part a perception that the raising of concerns was not welcome by senior management, and in part the very human reluctance to risk job security and potential opprobrium.” (p. 174) 
Quote 4d: "the management was a very inwards facing organisation, with a poor or defensive engagement with external bodies, including the HCC [Healthcare Commission] " (p. 171)

Quote 4e: “Generic standards were formulated not by the regulator but by the Government, thereby inhibiting the engagement with the standards of those working in the system (...) This must have contributed to the impression that the process was government controlled and thereby reinforced the disengagement of frontline clinicians.” (p. 54)

\section{Lack of Responsiveness}

There is clear evidence to suggest that problems were highlighted and raised from a number of actors including agencies, staff, clinicians, public, and patients, yet the case demonstrates a lack of urgency among actors to address and respond to concerns raised (see Quote 5a). The inaction of actors that might have responded to such concerns and the lack of corrective actions appear to be associated with a culture of (1) false assurance, (2) ignorance or avoidance, (3) underestimation of risks and concerns, and (4) waiting and seeing (see Quote 5b). In other words, a lack of responsiveness is reflected in both the norms, rules, and beliefs (cf. culture of ignorance and avoidance) and actions (cf. lack of corrective action). Moreover, this lack of responsiveness was found between actors at multiple levels across the system, such as hospital management (see Quote 5c), local GPs (see Quote 5d), strategic health authorities (see Quote 5e), resulting in a lack of responsiveness at the level of the NHS system.

Quote 5a: "There is no evidence that she was then required by those higher up in the system to take any further action, or that anything else was done until the information 
was used to inform the core standards risk-based assessment the following year" ( $p$. 860)

Quote 5b: "there was a need, in the interests of patients, for joint action by all those in a position to take it. While some steps were taken, the impression given has been one of waiting to see the outcome of the investigation rather than to accept that there was a current fundamental crisis giving rise to risks to patient care.

Quote 5c: "There was an unacceptable delay in addressing the issue of shortage of skilled nursing staff. There can be little doubt that the reason for the slow progress in the review, and the slowness of the Board to inject the necessary funds and a sense of real urgency into the process, was the priority given to ensuring that the Trust books were in order for the FT application." (p. 45)

Quote 5d: "local GPs only expressed substantive concern about the quality of care at the Trust after the announcement of the HCC investigation, when it had become obvious there were issues and when they were specifically asked.” (p. 47)

Quote 5e: "concerns were raised by external reviews, indicating the possibility of serious deficiencies affecting the safety of patients and the quality of care they received. These were known to SaSSHA, but there was no sense of urgency in ensuring that they had been addressed effectively.” (p. 736).

\section{Discussion}

SDL holds that actors in complex networks are driven by their respective goals and interests enabled and constrained by institutional logics, which involve institutional rules, norms, and beliefs and sets of interrelated institutions (Vargo and Lusch, 2016). In the Mid-Staffordshire 
case, patient care and business logic act as competing institutional logics within the network, in that these logics reflect divergent and even conflicting rules, norms, beliefs, and interests. This finding is in line with the view that public health service networks incorporate elements from different institutional logics that are not always compatible (Pache and Santos, 2013). Moreover, Vargo and Lusch (2016) confirm that institutional logics cannot only intersect and overlap but also create conflicting views on value. Based on the case analysis it is posited that competing institutional logics are the origin of imbalance in the studied complex network, where the legitimate interests of patients and the public are not secured. However, it is the way in which different actors in complex service networks deal with competing institutional logics that explains imbalances, rather than competing logics alone. In other words, imbalance can only occur if complex service networks are characterized by competing institutional logics, but competing institutional logics do not necessarily lead to imbalance. Therefore, we propose that competing institutional logics are the origin and not the driver of imbalance:

P1: Competing institutional logics are the origin of imbalance in complex service networks.

We argue that complex service networks characterized by competing institutional logics, as exemplified by the Mid-Staffordshire case, inevitably make achieving a perfect balance impossible, as the needs and wants of diverse actors cannot be fully prioritized at the same time. In the meanwhile, it is important to note that imbalance is not inherently good or bad, for example, at low to moderate degrees of imbalance complex service networks may not secure legitimate interests but still perform well and create value. Optimal value creation in networks charactized by competing institutional logics is achieved when the needs, wants, and interests of each actor are secured to a reasonable degree. The case evidence, however, 
suggests that different actors within the system adopted business logic at the detriment of patient care logic. In this situation, the needs, wants, and interests of patients and the public are not at all secured (high degrees of imbalance), leading to value deteroriation and even destruction as reflected in shocking levels of patient dissatisfaction and mortality rates. Building on this evidence, our second proposition contends:

P2: In complex service networks, there is a threshold level of imbalance beyond which value creation (economic or quality) will deteriorate and taken to the extreme complete destruction of any value will occur.

Interestingly, the Mid-Staffordshire case also provides insight into the conditions under which competing institutional logics exceed the threshold level of imbalance beyond which value deterioriation and destruction occur. Specifically, the findings point to four moderating factors that drive the degree to which competing institutional logics can generate imbalance in the network to the extent that value deterioriation and destruction occur. As mentioned in the findings section, in line with SDL each of these factors reflect actions and institutional logics in the form of rules, norms, and beliefs that enable and constrain balance. As a consequence, these findings support the view that actions and institutions of one actor might both facilitate and hinder the creation of value for other often loosely coupled actors in complex service networks (Frow and Payne, 2011; Fry and Polonsky, 2004; Plé and Cáceres, 2010). The case evidence, however, suggests that the impact of actions and institutions of one actor are intensified by similar actions and institutions of other actors. Indeed, extant research suggests that a multitude of actors in complex service network jointly provide the context through which value gains its individual and collective assessment (Patricio et al., 2011; Pinho et al., 2014; Vargo and Lusch, 2008, 2011). If multiple actors show similar actions and institutions, these actors cumulatively contribute to making actions and institutions desirable, 
proper, or appropriate-a process labeled as institutionalization-throughout the service network (Suchman 1995). Vargo and Lusch (2016) confirm that service networks constrain and coordinate themselves through institutional logics at various levels of aggregation. By showing that institutional logics and actions related to accountability, communication, engagement, and responsiveness moderate the impact of competing institutional logics on imbalance in the studied service network, the case evidence also provides insight into the concretization of actions and institutional logics that facilitate and/or hinder value creation. First, it is posited that the prevalence of these moderating factors in the network will determine the degree of imbalance generated by competing institutional logics. The case illustrates that as these moderating factors deplete, competing institutional logics will likely generate imbalance in the network to a greater degree. Therefore, it is proposed that:

P3: Low levels of accountability, communication, engagement, and responsiveness within the network will intensify the degree to which competing institutional logics increase imbalance in complex service network.

While the case study analysis uncovers the drivers of imbalance in a public health service network, conversely it seems plausible that when prevalent in the network these factors will serve to foster balance. In other words, it is postulated that the presence of appropriate levels of accountability, communication, engagement, and responsiveness will mitigate the generation of imbalance from competing institutional logics. This assumption finds support in previous literature that indicates that the presence of clear role division (cf. accountability), and dialogue and knowledge sharing (cf. communication) advances the functioning of a service network (e.g., Frow and Payne 2011, Hakanen and Jaakkola, 2012, Hillebrand et al. 2015). In sum, the following is proposed: 
P4: Appropriate levels of accountability, communication, engagement, and responsiveness within the network will mitigate the degree to which competing institutional logics increase imbalance in a complex service network.

Figure 1 draws together these propositions and illustrates that balance in public health service networks is a dynamic phenomenon. The origin of imbalance is found in competing institutional logics. In the context of public health service networks, business logic competes with patient care logic. If either dominates beyond a certain threshold point, either quality of care or economic performance deteriorates and becomes unsustainable (see Figure 1). It is suggested that value co-creation for all actors (i.e., balanced centricity) is achievable in complex service networks when competing institutional logics are effectively managed and balanced. This balancing act is a dynamic phenomenon of constant iteration between network actors, facilitated or hindered by the levels of accountability, communication, engagement and responsiveness within the service network.

\section{Please insert Figure 1 here}

\section{Research Implications}

\section{Theoretical Contributions}

This study explored the origin and drivers of imbalance in a public health service network, a context that is of great importance both in terms of citizens' wellbeing as well as public spending, but at the same time complex and evidently prone to disturbances. The point of departure for the study was the concept of balanced centricity (Gummesson, 2007, 2008) that urges organizations to consider the interests of all actors in their network, a view closely aligned with stakeholder theory (e.g., Hillebrand et al., 2015; Donaldson and Preston, 1995). 
The balanced centricity concept draws attention to the notion that each actor in a service network is driven by their respective needs, wants and goals, and a failure to take different aspirations into account will result in imbalance particularly in complex networks. Inspired by this concept, this paper analyzed the well-documented case of the Mid-Staffordshire NHS Trust to identify root causes of a health service network dysfunction that resulted in diminished patient care quality.

This study finds that the primary underlying origin of network imbalance is the competing institutional logics of those actors in the network. In other words, complex service networks are characterized by the inherent existence of multiple parallel institutional arrangements (Vargo and Lusch, 2016), but the degree to which different institutional arrangements compete with one another involves risk of an imbalanced situation. The degree to which imbalance exceeds the threshold level beyond which value deterioriation and destruction occur, however, depends on how different actors in complex service networks deal with these competing institutional logics. Specifically, this research suggests that complex service networks characterized by competing institutional logics can achieve optimal value creation when a balance is found between divergent competing logics. The study further identifies four key factors (accountability, communication, engagement, and responsiveness) that are proposed to moderate the propensity of imbalance generated by competing institutional logics. In sum, competing logics alone do not determine imbalance, but rather but the way in which different actors in complex service networks deal with these competing logics explain imbalance and network dysfunction.

These findings contribute to previous research in several streams. First, our findings contribute to the area of service networks. Previous research has provided insight on how value co-creation occurs in the interaction between actors in complex service networks (e.g., Pinho et al., 2014; Frow and Payne, 2011; Vargo and Lusch, 2016) and how multi-actor 
service networks should be designed to create smooth customer journeys through the system (e.g., Patricio et al., 2008; Patricio et al., 2011; Tax et al., 2013). This study adds to previous research by highlighting the dark side of multi-actor service networks and pinpointing potential sources of hindrances to value co-creation and superior customer experiences.

Specifically, this paper identifies imbalance as the underlying cause of network dysfunction. As a consequence, this paper elaborates on the concept of balanced centricity which was originally presented as a potentially utopian one (Gummesson, 2008), but has remained sparsely studied. This paper brings this concept to an actionable (realistic) level and discusses to what extent this concept is viable and what factors hinder or enable it. Previous research suggests that network actors can adopt different strategies to deal with competing interests or logics. Pache and Santos (2013) make a distinction between symbolically supporting one logic while implementing another logic (decoupling) and crafting a balance between competing logics (compromising). Conceptually, Hillebrand et al. (2015) seem to support the compromising strategy by stating that understanding the whole network and learning from competing interests of the network actors is preferable to ignoring or suppressing competing interests. The case evidence supports this reasoning by demonstrating the disastrous implications of neglecting the causes of imbalance in the network. Moreover, this paper offers insight into how balance between competing logics may be crafted in a complex service network by fostering accountability, communication, engagement, and responsiveness in the network.

By providing insight into the importance of and mechanisms by which balanced centricity may be realized, this study highlights a dynamic, interactive and iterative approach to stakeholder theory. Stakeholders themselves are interrelated in networks, thus addressing the needs of only one specific stakeholder group within a network may subsequently impact relationships with other stakeholders in the network. As a consequence, there is a need to 
reflect the multiple influences from the entire stakeholder set. The study findings develop understanding into the role of conflicting logics. While accommodating the diverse and divergent needs of an entire stakeholder set is challenging, this balancing act can be fostered by the four identified factors that are critical for minimizing imbalance in service networks.

\section{Avenues for Future Research}

There are many opportunities for future research in line with the present study. For example it is possible to look upon the limitations of the present study and pinpoint the need for a different methodological departure. This study relies on secondary data drawn from a public inquiry report. Although the purpose of the public inquiry was in line with the research purpose (i.e., understanding why the interests of patients were not taken into consideration) and it is a strength that these data are not created as a result of our case study (Yin 2014), we had no control over sampling and data collection methods. In the first-stage of investigation the inquiry focused on origins and drivers of below expected service standards among hospital staff and management. The inquiry, however, revealed that the wider network also played an important role, leading to a focus on the wider system in a second stage of investigation. The two-stage approach suggests that the public inquiry was open to address shortcomings of the sampling and data collection method.

Moreover, the public inquiry may be charged with 'pointing the finger' after the fact. This bias, however, cannot be avoided, in that we can only rely on retrospective data to study the Mid-Staffordshire case. However, the selection of a case to gather prospective data is difficult due to uncertainty about cases in which imbalance may occur. Based upon our research findings in relation to the origins and drivers of imbalance, future research might select multiple cases to gather both prospective and retrospective data to gain more insight into the issues related to balanced centricity. 
Furthermore, the report primarily focused on the negative outcomes of imbalance for one group of actors in particular, the patients, and while this has provided insights related to the causes of imbalance originating from all actors in the network, it would have been fruitful to more thoroughly look into the other actors experiences during the same period. Unfortunately, this was beyond the scope of the secondary data drawn upon. One conclusion is that empirical investigation of balanced centricity would require a rather sophisticated methodology to fully understand the imbalanced situation for all actors, given the complexity of such service networks. This is an open avenue for future research.

A related topic is the dynamics of balancing interests. If we move away from the dyadic relationship of "customers" and "producers" and claim that different actor needs require different outcomes, there is a call for future studies exploring service networks that might reveal different actors’ rationale. Many questions remain unanswered, for example, does a high level of diversity among actors create a higher prevalence of competing institutional logics? What about the interplay of institutional logics specifically on different actors? Each actor may be affected by multiple logics, e.g. a doctor as a member of the medical profession but also as an administrator may be torn between two logics, and so there is a need to further investigate the notion of competing institutional logics as this may be more complex in itself. It is also important to study how service networks could be managed to better develop and maintain balance, for example can individual actors take the role of seeking balance by mediating between relevant actors? And what management activities are relevant in those cases? While we shed light on these issues by uncovering appropriate mechanisms that when fostered can be used to manage balance between divergent logics (e.g., accountability, communication, engagement, and responsiveness), the implementation of these mechanisms in practice warrants exploration. 


\section{Practical Contributions}

The present study has both administrative and policy implications. First, from an administrative perspective the importance of acknowledging competing institutional logics cannot be downplayed and must be taken into account when designing management and measurement systems. While individual members in organizations tend to do what is "locally reasonable”, the Mid-Staffordshire NHS Trust case shows how a network in imbalance can lead to disastrous service outcomes. The paper gives some direction for how to keep networks in balance and to prevent the narrow concern of actors that may undermine balance in a complex service network. Development work in areas like communication, accountability, engagement and responsiveness seems well invested.

Second, at the broader policy level, with decreasing budgets and resource depletion continuing into the future, identifying how to do more with less becomes ever necessary for public services. While balancing conflicting institutional logics and their associated competing goals is inherently difficult within complex public health service networks, pinpointing conditions that may serve to catalyze imbalance (e.g., accountability, communication, engagement, and responsiveness at low levels) but also serve to manage balance (e.g., accountability, communication, engagement, and responsiveness at high levels) offers critical insight into how policy may be able to shape balanced centricity. It is these specific factors that must be collectively pursued and therefore mandated by policy to ensure that they are not neglected since competing institutional logics are present in all public health service networks and by implication, the potential for imbalance (and the associated negative consequences) is present in all such service networks.

\section{Conclusion}

Public service networks are inherently complex as they comprise of many interrelated actors 
of which most are driven by divergent interests. Drawing on the balanced centricity perspective, this paper explores the causes of imbalance in a public health service network. Adopting the theoretical lenses of SDL and stakeholder theory, the origin of imbalance is found to stem from competing institutional logics of various actors (patients/public, employees, managers, and a multiplicity of regulatory bodies), but the degree to which these competing institutional logics lead to imbalance is moderated by accountability, communication, engagement, and responsiveness within the service network. In other words, it is the way in which different actors in complex service networks (mis)manage competing institutional logics that can explains imbalance, not competing logics in themselves. By examining imbalance as the underlying cause of network dysfunction, this research also contributes to understanding of the dynamics in, and performance of, complex service networks. While the existence of multiple parallel institutional arrangements makes networks inherently imbalanced, value creation can be achieved when the appropriate mechanismsincluding accountability, communication, engagement, and responsiveness-are fostered to better manage balance between divergent logics.

\section{References}

Berry, L.L., Mirabito, A.M., and Berwick, D.M. (2004), “A health care agenda for business”, Sloan Management Review, Vol. 45 No. 4, pp. 56-64.

Berry, L.L., and Bendapudi, N. (2007), “Health care a fertile field for service research”, Journal of Service Research, Vol. 10 No. 2, pp. 111-122.

Bitner, M. J., Ostrom, A. L. \& Morgan, F. N. (2008), "Service blueprinting: A practical technique for service innovation", California Management Review, Vol. 50 No. 3, pp. 66-94. 
Campbell, D. (2014), NHS finances in crisis due to rising demand and budget cuts, The Guardian [online] 5 October. Available at:

http://www.theguardian.com/society/2014/oct/05/nhs-finances-crisis-rising-demandbudget-cuts-30-billion-pound-deficit-2020. [Accessed 25 November 2015].

Campbell, D. (2013). Mid Staffs hospital scandal: the essential guide, The Guardian [online] 6 February. Available at: http://www.theguardian.com/society/2013/feb/06/midstaffs-hospital-scandal-guide. [Accessed 8 January 2016].

Campbell, D. and Duncan, P. (2016), 10 truths about Britain's health service, The Guardian [online] 18 January. Available at: http://www.theguardian.com/society/2016/jan/18/10-truths-about-britains-healthservice. [Accessed 18 March 2016].

Donaldson, T. \& Preston, L. E. (1995), "The stakeholder theory of the corporation - concepts, evidence, and implications", Academy of Management Review, Vol. 20 No. 1, pp. 6591.

Duhachek, A. (2005), "Coping: A multidimensional, hierarchical framework of responses to stressful consumption episodes", Journal of Consumer Research, Vol. 32 No. 1, pp.41-53.

Eisenhardt, K.M. (1989), "Building theories from case study research", Academy of Management Review, Vol. 14 No. 4, pp.532-550.

Everett, M. \& Borgatti, S. P. (2005), "Ego network betweenness", Social networks, Vol. 27 No. 1, pp. 31-38.

Francis, R. 2013. Report of the Mid Staffordshire NHS Foundation Trust public inquiry. Executive summary. Chair Robert Francis. Hc 947. Mid Staffordshire NHS Foundation Trust Public Inquiry. London. 
Frow, P. \& Payne, A. (2011), "A stakeholder perspective of the value proposition concept", European Journal of Marketing, Vol. 45 No. 1/2, pp. 223-240.

Fry, M.-L. \& Polonsky, M. J. (2004), "Examining the unintended consequences of marketing", Journal of Business Research, Vol. 57 No. 11, pp. 1303-1306.

Gummesson, E. (2007), "Exit service marketing - enter service marketing", The Journal of Consumer Behaviour, Vol. 6 No. 2, pp. 113-141.

Gummesson, E. (2008), "Extending the service-dominant logic: From customer centricity to balanced centricity", Journal of the Academy of Marketing Science, Vol. 36 No. 1, pp. $15-17$.

Hakanen, T. \& Jaakkola, E. (2012) "Co-creating customer-focused solutions within business networks: a service perspective", Journal of Service Management, Vol. 23 Iss: 4, pp.593-611.

Hillebrand, B., Driessen, P. H. \& Koll, O. (2015), "Stakeholder marketing: Theoretical foundations and required capabilities", Journal of the Academy of Marketing Science, Vol. 43 No. 4, pp. 411-428.

Holmes, D. (2013), "Mid staffordshire scandal highlights NHS cultural crisis", Lancet, Vol. 381 No. 9866, pp. 521-522.

Hutchison, J.S. (2016). Scandals in health-care: their impact on health policy and nursing. Nursing Inquiry, Vol. 23 No. 1, pp. 32-41.

Ingleby, D., McKee, M., Mladovsky, P. \& Rechel, B. (2012), "How the NHS measures up to other health systems”, British Medical Journal Vol. 344, pp. 1079-1084.

Jaakkola, E., and Hakanen, T. (2013). "Value co-creation in solution networks”, Industrial Marketing Management, Vol. 42 No. 1, pp. 47-58.

Lusch, R. F., Vargo, S. L. \& Tanniru, M. (2010), "Service, value networks and learning", Journal of the Academy of Marketing Science, Vol. 38 No. 1, pp. 19-31. 
Marsden, P. V. (1990), "Network data and measurement", Annual Review of Sociology, Vol. 16, pp. 435-463.

McColl-Kennedy, J. R., Vargo, S. L., Dagger, T. S., Sweeney, J. C. \& van Kasteren, Y. (2012), "Health care customer value cocreation practice styles", Journal of Service Research, Vol. 15 No. 4, pp. 370-389.

Moller, K. K. \& Halinen, A. (1999), "Business relationships and networks: Managerial challenge of network era", Industrial Marketing Management, Vol. 28 No. 5, pp. 413427.

NHS (2016), NHS authorities and trusts, retrieved from http://www.nhs.uk/NHSEngland/thenhs/about/Pages/authoritiesandtrusts.aspx

NHS England. (2014), Understanding the new NHS, British Medical Journal. London.

Pache, A. C. \& Santos, F. (2013). Inside the hybrid organization: Selective coupling as a response to competing institutional logics. Academy of Management Journal, Vol. 56 No. 4, pp. 972-1001.

Patricio, L., Fisk, R. P., Cunha, J. F. E. \& Constantine, L. (2011), "Multilevel service design: From customer value constellation to service experience blueprinting", Journal of Service Research, Vol. 14 No. 2, pp. 180-200.

Pinho, N., Beirão, G., Patrício, L. \& P. Fisk, R. (2014), "Understanding value co-creation in complex services with many actors", Journal of Service Management, Vol. 25 No. 4, pp. 470-493.

Plé, L. \& Cáceres, R. C. (2010), "Not always co-creation: Introducing interactional codestruction of value in service-dominant logic", Journal of Services Marketing, Vol. 24 No. 6, pp. 430 - 437. 
Provan, K. G., Fish, A. \& Sydow, J. (2007), "Interorganizational networks at the network level: A review of the empirical literature on whole networks", Journal of Management, Vol. 33 No. 3, pp. 479-516.

Quero, M. J. \& Ventura, R. (2015), "The role of balanced centricity in the spanish creative industries adopting a crowd-funding organisational model", Journal of Service Theory and Practice, Vol. 25 No. 2, pp. 122-139.

Raghunathan, R., Pham, M.T., and Corfman, K.P. (2006), "Informational properties of anxiety and sadness, and displaced coping", Journal of Consumer Research, Vol. 32 No. 4, pp. 596-601.

Tax, S. S., McCutcheon, D. \& Wilkinson, I. F. (2013), "The service delivery network (SDN): A customer-centric perspective of the customer journey", Journal of Service Research, Vol. 16 No. 4, pp. 454-470.

Tax, S. S., Smith, A. K., and Murali, C. (2011), “Tangled web or a tidy knot? Assessing failure and recovery in a service network”. Paper presented at Naples Forum on Service, 14-17th June 2011.

Teixeira, J., Patricio, L., Nunes, N. J., Nobrega, L., Fisk, R. P. \& Constantine, L. (2012), "Customer experience modeling: From customer experience to service design", Journal of Service Management, Vol. 23 No. 3, pp. 362-376.

van Riel, A. C. R., Calabretta, G., Driessen, P. H., Hillebrand, B., Humphreys, A., Krafft, M. \& Beckers, S. F. M. (2013), "Consumer perceptions of service constellations: Implications for service innovation", Journal of Service Management, Vol. 24 No. 3, pp. 314-329.

Vargo, S. L. \& Lusch, R. F. (2008), "Service-dominant logic: Continuing the evolution", Journal of the Academy of Marketing Science, Vol. 36 No. 1, pp. 1-10. 
Vargo, S. L. \& Lusch, R. F. (2011), "It's all b2b ... And beyond: Toward a systems perspective of the market", Industrial Marketing Management, Vol. 40 No. 2, pp. 181-187.

Vargo, S. L. \& Lusch, R. F. (2016), "Institutions and axioms: An extension and update of service-dominant logic", Journal of the Academy of Marketing Science, Vol. 44 No. 1, pp. 5-23.

Verleye, K., Gemmel, P. \& Rangarajan, D. (2016), "Engaged customers as job resources or demands for frontline employees?", Journal of Service Theory and Practice, forthcoming.

Voss, C. A. \& Hsuan, J. (2009). “Service architecture and modularity”, Decision Sciences, Vol. 40 No. 3, pp. 541-569.

WHO (2016), Efficiency and universal health coverage, retrieved from http://www.who.int/health_financing/topics/efficiency/universal-health-coverage/en/ Yin, R.K. (2014), Case Study Research. Design and Methods. Los Angeles: Sage Publications. 